\title{
Feasibility and safety of high-dose adenosine perfusion cardiovascular magnetic resonance imaging
} Theodoros D Karamitsos*, Ntobeko BA Ntusi, Jane M Francis, Cameron J Holloway, Saul G Myerson,
Stefan Neubauer

From 2011 SCMR/Euro CMR Joint Scientific Sessions

Nice, France. 3-6 February 2011

\section{Objective}

The aim of the present study was to assess the tolerance and safety of a high-dose adenosine protocol $(210 \mathrm{mcg} /$ $\mathrm{kg} / \mathrm{min}$ ) in patients with inadequate hemodynamic response to the standard adenosine dose $(140 \mathrm{mcg} / \mathrm{kg} /$ min) when undergoing CMR perfusion imaging.

\section{Introduction}

Adenosine is the most widely used vasodilator stress agent for Cardiovascular Magnetic Resonance (CMR) perfusion studies. With the standard dose of $140 \mathrm{mcg} /$ $\mathrm{kg} / \mathrm{min}$ some patients fail to demonstrate characteristic hemodynamic changes: a significant increase in heart rate (HR) and mild decrease in systolic blood pressure (SBP). Whether an increase in the rate of adenosine infusion would improve peripheral and, likely, coronary vasodilatation in those patients is unknown.

\section{Methods}

98 consecutive patients with known or suspected coronary artery disease (CAD) underwent CMR perfusion imaging at 1.5 Tesla. Subjects were screened for contraindications to adenosine, and an electrocardiogram was performed prior to the scan. All patients initially received the standard adenosine protocol $(140 \mathrm{mcg} / \mathrm{kg} /$ min for at least 3 minutes). If the hemodynamic response was inadequate (HR increase $<10 \mathrm{bpm}$ or SBP decrease $<10 \mathrm{mmHg}$ ) then the infusion rate was increased up to a maximum of $210 \mathrm{mcg} / \mathrm{kg} / \mathrm{min}$ (maximal infusion duration 7 minutes).

\footnotetext{
Oxford Centre for Clinical Magnetic Resonance Research, OXFORD, UK
} Full list of author information is available at the end of the article

\section{Results}

All patients successfully completed the CMR scan. Of a total of 98 patients, 18 (18\%) did not demonstrate evidence of a significant increase in HR or decrease in SBP under the standard adenosine infusion rate. Following the increase in the rate of infusion, 16 out of those 18 patients showed an adequate hemodynamic response. The hemodynamic parameters at rest and during adenosine stress are shown on table 2. Two patients of the standard infusion group and one patient of the highdose group developed transient advanced AV block. Significantly more patients complained of chest pain in the high-dose group $(61 \%$ vs. $29 \%, \mathrm{p}=0.009)$.On multivariate analysis, age $>65$ years and ejection fraction $<57 \%$ were the only independent predictors of blunted haemodynamic responsiveness to adenosine.

Table 1 Hemodynamic Parameters at Rest and During Adenosine Stress

\begin{tabular}{llllllll}
\hline $\begin{array}{l}\text { Standard dose Adenosine } \\
(\mathbf{n = 8 0})\end{array}$ & \multicolumn{7}{c}{ High dose Adenosine $(\mathbf{n}=\mathbf{1 8})$} \\
\hline & Rest & Peak & p-value & Rest & $\begin{array}{l}\mathbf{1 4 0} \boldsymbol{\mu g} / \\
\mathbf{k g} / \mathbf{m i n}\end{array}$ & Peak & p-value \\
\hline $\mathrm{HR}$ & $70 \pm 13$ & $96 \pm 16$ & $<0.001$ & $66 \pm 12$ & $75 \pm 11$ & 81 & 0.011 \\
$(\mathrm{bpm})$ & & & & & & $\pm 18^{*}$ & \\
\hline $\mathrm{SBP}$ & 137 & 139 & 0.21 & 139 & $134 \pm 24$ & 132 & 0.68 \\
$(\mathrm{mmHg})$ & \pm 18 & \pm 19 & & \pm 23 & & \pm 22 & \\
\hline $\mathrm{DBP}$ & $80 \pm 12$ & $81 \pm 12$ & 0.55 & $82 \pm 12$ & $79 \pm 11$ & $77 \pm 14$ & 0.57 \\
$(\mathrm{mmHg})$ & & & & & & & \\
\hline $\mathrm{RPP}$ & 9639 & 13304 & $<0.001$ & 8975 & 9945 & 10672 & 0.07 \\
& \pm 2399 & \pm 2781 & & \pm 1909 & \pm 1694 & \pm 2787 & \\
\hline
\end{tabular}

* $\mathrm{p}<0.05$ vs. rest.

DBP, diastolic blood pressure; HR, heart rate; RPP, rate pressure product; SBP, systolic blood pressure. 


\section{Conclusions}

A substantial number of patients do not show adequate peripheral hemodynamic response to standard-dose adenosine stress during perfusion CMR imaging. Age and reduced ejection fraction are predictors of inadequate response to standard dose adenosine. Our initial experience with a high-dose adenosine protocol (up to 210 $\mathrm{mcg} / \mathrm{kg} / \mathrm{min}$ ) shows that it is well tolerated and results in adequate hemodynamic response in nearly all patients.

Published: 2 February 2011

doi:10.1186/1532-429X-13-S1-P105

Cite this article as: Karamitsos et al:: Feasibility and safety of high-dose adenosine perfusion cardiovascular magnetic resonance imaging. Journal of Cardiovascular Magnetic Resonance 2011 13(Suppl 1):P105.

Submit your next manuscript to BioMed Central and take full advantage of:

- Convenient online submission

- Thorough peer review

- No space constraints or color figure charges

- Immediate publication on acceptance

- Inclusion in PubMed, CAS, Scopus and Google Scholar

- Research which is freely available for redistribution

Submit your manuscript at www.biomedcentral.com/submit
C Biomed Central 